\title{
Effect of the Mechanical Treatment of Alumina on Thermal, Morphological and Dielectric Properties of LDPE $/ \mathrm{Al}_{2} \mathrm{O}_{3}$ Composites
}

\author{
F.Z. Benabid ${ }^{\mathrm{a}, \star}$, O.K. Mallem ${ }^{\mathrm{a}}$, F. Zouai ${ }^{\mathrm{b}}$, M.E. Cagiao $^{c}{ }^{\left(\mathbb{D}^{\S}\right.}{ }^{\S}$, and D. Benachour ${ }^{\mathrm{a}}$ \\ ${ }^{a}$ LMPMP, Faculté de Technologie, Université Ferhat ABBAS Sétif-1, Algeria. \\ ${ }^{b}$ Unité de Recherche Matériaux Emergents, Université Ferhat ABBAS Sétif-1, Algeria. \\ ${ }^{c}$ Macromolecular Physics, Instituto de Estructura de la Materia, CSIC, Serrano 119, 28006 Madrid, Spain.
}

Received 21 November 2017, revised 27 June 2018, accepted 8 September 2018.

\begin{abstract}
Composites of LDPE filled with different amounts of alumina $\mathrm{Al}_{2} \mathrm{O}_{3}$ were prepared using co-mixing technique and melt-mixing. This technique, which is easy, non-toxic and inexpensive, has been successfully used in our laboratory for different polyolefins/ metal oxides nanocomposites elaboration. Samples containing $0.5,1$ and $2 \mathrm{wt} \%$ of alumina, were prepared by melt-mixing at $190{ }^{\circ} \mathrm{C}$ without any chemical treatment or coupling agent. The effect of alumina treatment was studied. $\mathrm{The}^{\mathrm{Al}} \mathrm{Ol}_{2} \mathrm{O}_{3}$ was first co-mixed with the stearic acid then added to the polymer. The stearic acid melts at $70{ }^{\circ} \mathrm{C}$, thus ensuring the dispersion of the covered filler particles into the polymeric matrix, which leads to better experimental results. The morphological characterization was carried out by scanning electron microscopy (SEM) and atomic force microscopy (AFM). The thermal properties were investigated by thermogravimetric analysis (TGA). The electrical conductivity was also studied. The microstructure-properties relationships were also investigated. The composites prepared with the co-mixed $\mathrm{Al}_{2} \mathrm{O}_{3}$ were compared to those prepared with the neat $\mathrm{Al}_{2} \mathrm{O}_{3}$. The thermogravimetric (TGA) results showed an enhancement of $55{ }^{\circ} \mathrm{C}$ in the thermal stability for the $\mathrm{LDPE} / \mathrm{Al}_{2} \mathrm{O}_{3}$ composition containing $1 \mathrm{wt} \%$ of treated $\mathrm{Al}_{2} \mathrm{O}_{3}$. The electrical conductivity results showed also an optimum value of 6.6.10-7 $\Omega^{-1} \mathrm{~cm}^{-1}$ for the same composition.
\end{abstract}

KEYWORDS

Composites, LDPE, $\mathrm{Al}_{2} \mathrm{O}_{3}$ nanoparticles, stearic acid, co-mixing method.

\section{Introduction}

The preparation of composite materials with reinforcing fillers is one of the successful methods used to improve the properties of polymers. The idea is to incorporate the filler nanoparticles into the polymer matrix. The properties of the resulting polymer/filler composites depend on the characteristics, i.e. dimensions, shapes, etc., of the fillers, and also on the interfacial bonding strength. ${ }^{1}$ Due to their good specific properties, this kind of materials has attracted great interest. Many different materials have been used as fillers for polymers. Thus, glass fibres, and more recently, natural fibres have been used in the preparation of polymer nanocomposites. ${ }^{2-7}$ But the addition of nanosized inorganic particles has also shown to be very useful in the enhancement of thermal and mechanical polymer properties. For instance, clay has been widely used in the preparation of composites for polymers such as $\mathrm{PP}_{,}^{8,9}$ poly(vinylidene fluoride) $\mathrm{PVDF}^{10}$ or its blends with poly (methyl methacrylate) PMMA. ${ }^{11}$ Finally, metallic oxides $\left(\mathrm{ZnO}, \mathrm{MgO}, \mathrm{TiO}_{2}, \mathrm{Al}_{2} \mathrm{O}_{3} \mathrm{CuO}\right.$, etc.) are being explored as potential polymer fillers in the preparation of nanocomposites. Thus, for instance, Ren GuiHua et al. studied the dielectric, optical and thermal properties of low-density polyethylene (LDPE)/ZnO hybrid films. ${ }^{12}$ Their results show that both the dielectric constant and the dielectric loss of the composites increase with increasing $\mathrm{ZnO}$ weight fraction. Moreover, the thermal properties of the LDPE/ZnO hybrid films are improved. On the other hand, K. Ishimoto et $a l .{ }^{13}$ studied the

* To whom correspondence should be addressed. E-mail: fzbenabid @yahoo.fr dielectric properties of low-density polyethylene/MgO composites with different size fillers. At all the measurement temperatures, the conductivity is decreased and the permittivity is increased by the addition of fillers, irrespective of their sizes. However, the conductivity decrease is more significant and the permittivity increase is suppressed more in the case of the nm fillers. In addition to this, O.O. Daramola et al. ${ }^{14}$ studied the tensile and hydrophilic properties of low-density polyethylene/ titania composites. Authors demonstrated that an optimum combination of mechanical and hydrophilic properties of low-density polyethylene for water-based applications can be achieved by filling the matrix with $1-3$ volume $\%$ of $\mathrm{TiO}_{2}$ particles, $0.5 \mu \mathrm{m}$ in size.

In this study, we present the results obtained in the preparation and characterization of LDPE-based nanocomposites, prepared with both pure and stearic acid-treated $\mathrm{Al}_{2} \mathrm{O}_{3}$

Low-density polyethylene (LDPE) is a commercial polymer with a wide range of applications. This polyolefin presents high flexibility, good processability and excellent resistance to dilute and concentrated acids, alcohols, esters and bases. ${ }^{15}$

Alumina $\mathrm{Al}_{2} \mathrm{O}_{3}$ was selected as a filler for the LDPE due to its excellent dielectric properties. Its surface treatment with stearic acid was carried out to improve the quality of polymer/filler interfaces, thus ensuring compatibility and good dispersion of the filler into the polymeric matrix.

Several researchers have studied the behaviour of the LDPE/ $\mathrm{Al}_{2} \mathrm{O}_{3}$ nanocomposites, ${ }^{16-18}$ Thus, Si-Jiao Wang et al. ${ }^{16}$ reported 
that the modified nano- $\mathrm{Al}_{2} \mathrm{O}_{3}$ particles with vinyl silane coupling can be homogeneously dispersed in LDPE matrix. Effects of $\gamma$-radiation on dielectric properties of LDPE- $\mathrm{Al}_{2} \mathrm{O}_{3}$ nanocomposites have been studied by F. Ciuprina et al. ${ }^{17}$ Finally, O.K. Mallem ${ }^{18}$ has investigated the physicochemical properties of LDPE $/ \mathrm{Al}_{2} \mathrm{O}_{3}$ and $\mathrm{PP} / \mathrm{Al}_{2} \mathrm{O}_{3}$ compositions.

\section{Experimental}

\subsection{Materials}

Low-density polyethylene LDPE (Sabic), from Saudi Basic Industries Corporation, was used as received. Density $=961 \mathrm{~kg}$ $\mathrm{m}^{-3}$. Melt flow rate $=0.7 \mathrm{~g} 10 \mathrm{~min}^{-1}$ (at $190^{\circ} \mathrm{C}$ and $2.16 \mathrm{~kg}$ ) Alumina $\mathrm{Al}_{2} \mathrm{O}_{3}$ was supplied by Aldrich Company. Molecular weight $=101.96 \mathrm{~g} \mathrm{~mol}^{-1}$. Particle sizes about $100 \mu \mathrm{m}$. Stearic acid was supplied by Merck. Bulk density: $400-500 \mathrm{~kg} \mathrm{~m}^{-3}$.

\subsection{Mechanical Treatment of $\mathrm{Al}_{2} \mathrm{O}_{3}$}

In the present work we deal with the use of the co-mixing method as a fast, inexpensive and non-harmful physical technique. In order to reduce the size of the alumina filler, it was ground using coffee grinder of Clatronic Bomann (see Fig. 1).

The use of the stearic acid, which is a lubricant for certain polymers, facilitates the dispersion of the $\mathrm{Al}_{2} \mathrm{O}_{3}$ particles into the LDPE matrix.

The presence of agglomerations in LDPE $/ \mathrm{Al}_{2} \mathrm{O}_{3}$ composites conventional elaboration techniques led us to use this innovative method. Properties were improved and no agglomerations were observed.

For the preparation of some samples, the $\mathrm{Al}_{2} \mathrm{O}_{3}$ was mechanically modified with stearic acid using the co-mixing method in order to improve the compatibility between the matrix (LDPE) and the filler $\left(\mathrm{Al}_{2} \mathrm{O}_{3}\right)$. Thus, the $\mathrm{Al}_{2} \mathrm{O}_{3}$ and the stearic acid at $50 / 50 \mathrm{wt} \%$ (each filler particle must be covered by the stearic acid in order to facilitate its dispersion into the LDPE matrix) were co-mixed.

\subsection{Nanocomposites Preparation}

Two series of compositions with different filler contents were prepared, one using the neat $\mathrm{Al}_{2} \mathrm{O}_{3}$, and the other one the stearic acid (treated one). The samples classified as 'BNA' were those prepared using the neat filler, whereas 'BA' designs the compositions prepared with the treated one. For this purpose, either the neat $\mathrm{Al}_{2} \mathrm{O}_{3}$, or the mixture $\mathrm{Al}_{2} \mathrm{O}_{3}$ /stearic acid were added to the LDPE in proportions of $0.5,1$ and $2 \mathrm{wt} \%$ by using a Brabender plastograph. The working conditions were the following: rotation speed $=30 \mathrm{rpm}$, temperature $=190{ }^{\circ} \mathrm{C}$. The total working time was $10 \mathrm{~min}$ : $3 \mathrm{~min}$ for the LDPE, in order to lower the viscosity, and then, $7 \mathrm{~min}$ more once the filler was added, to well disperse it into the polymeric matrix.

The different prepared formulations are included in Table 1.
Table 1 Different compositions of $\mathrm{LDPE} / \mathrm{Al}_{2} \mathrm{O}_{3}$.

\begin{tabular}{lclc}
\hline Sample & $\begin{array}{c}\text { Filler content } \\
\left.\text { (untreated } \mathrm{Al}_{2} \mathrm{O}_{3}\right)\end{array}$ & Sample & $\begin{array}{c}\text { Filler content } \\
\left(\text { treated } \mathrm{Al}_{2} \mathrm{O}_{3}\right) \\
/ \%\end{array}$ \\
\hline B & 0 & B & 0 \\
BNA0.5 & 0.5 & BA0.5 & 0.5 \\
BNA1 & 1 & BA1 & 1 \\
BNA2 & 2 & BA2 & 2 \\
\hline
\end{tabular}

\section{Characterization}

\subsection{Morphology}

The microstructure of the neat LDPE and the LDPE $/ \mathrm{Al}_{2} \mathrm{O}_{3}$ composites was investigated by scanning electron microscopy using an XL 30 ESEM equipment. The samples were analyzed without metallization of their surfaces.

In order to evaluate the efficiency of the stearic acid in covering the filler particles, the atomic force microscopy AFM technique has been used. The images were recorded using an AXIOSCOP 40 microscope with a frequency of $1 \mathrm{~Hz}$ and at a scale of $50 \mu \mathrm{m}$ ). The RMS roughness (root-mean-square height deviation) of the samples was obtained directly from the software of the AFM.

\subsection{Thermal Properties}

The thermogravimetric analysis (TGA) was carried out on a TGA 4000 instrument (Perkin Elmer), working in a nitrogen atmosphere. The tests were run at a heating rate of $20^{\circ} \mathrm{C} \mathrm{min}^{-1}$ in the temperature range $25-600{ }^{\circ} \mathrm{C}$.

\subsection{Dielectric Properties}

The dielectric measurements were carried out using a Hioki 3532 Hi-Tester using the four-point method.

\section{Results and Discussion}

\subsection{AFM Microscopy}

The AFM topographic images of the untreated and treated $\mathrm{Al}_{2} \mathrm{O}_{3}$ are represented in Fig. $2 \mathrm{a}$ and Fig. 2b, respectively. It is observed that the root-mean-square RMS value decreased from $334.05 \mathrm{~nm}$ to $63.25 \mathrm{~nm}$ for the treated $\mathrm{Al}_{2} \mathrm{O}_{3}$, which indicated that all alumina particles were covered by the stearic acid which ensure an excellent dispersion of the filler into the matrix: ${ }^{18}$ same observations have been reported by O.K. Mallem et al., they observed that the root mean square (RMS) value has decreased for the treated particles.

\subsection{SEM Microscopy}

The micrographs of the different compositions are presented
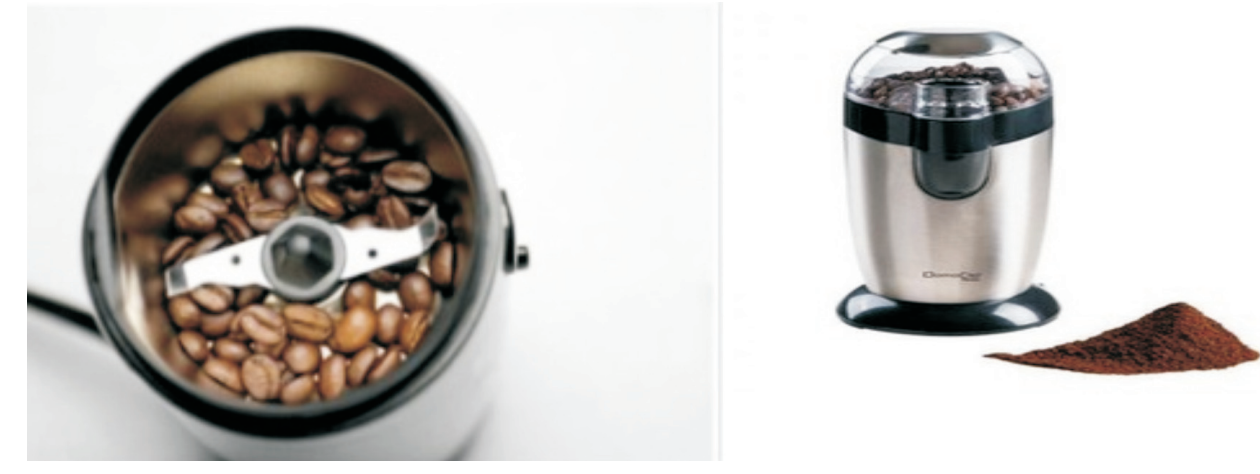

Figure 1 Image of Clatronic Bomann coffee grinder. 

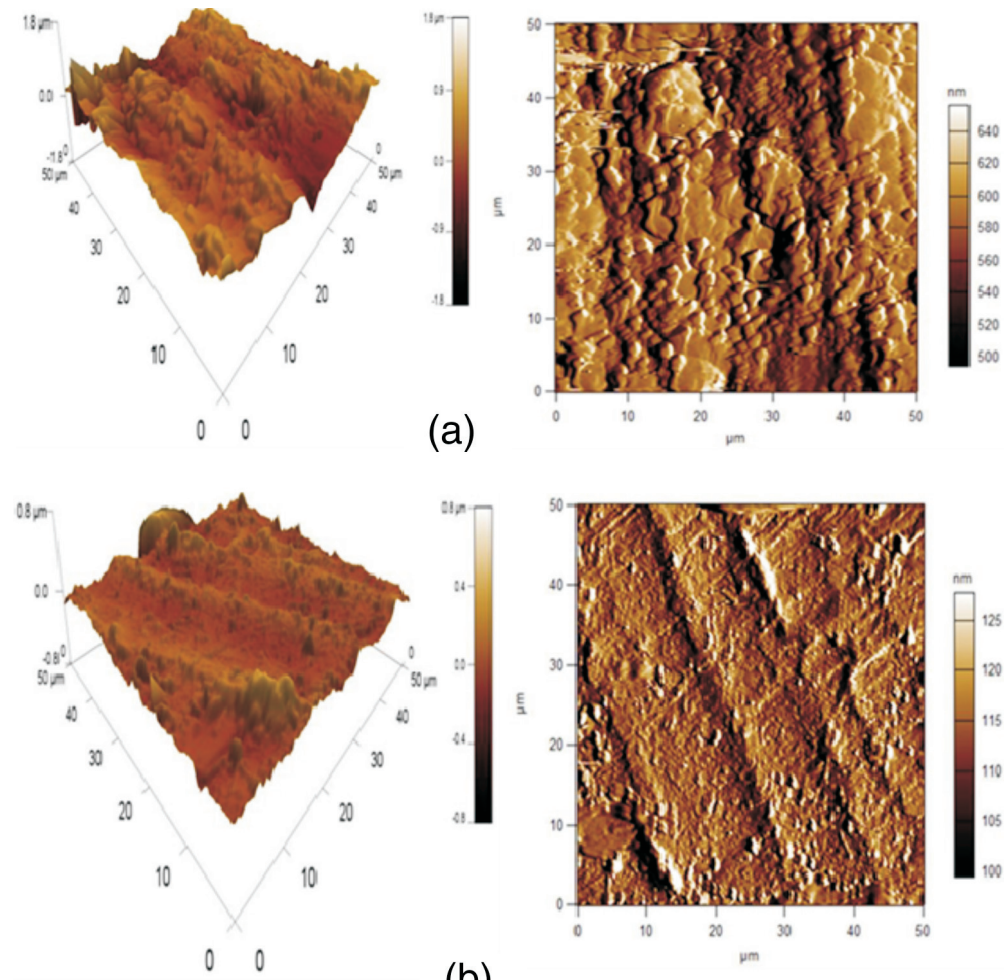

(b)

Figure 2 (a) AFM topographic images in of neat $\mathrm{Al}_{2} \mathrm{O}_{3}$ in three and two dimensions, respectively (b): AFM topographic images of stearic acid-treated $\mathrm{Al}_{2} \mathrm{O}_{3}$ in three and two dimensions, respectively.

in Fig. 3 which shows the effect of the incorporation of $1 \mathrm{wt} \%$ $\mathrm{Al}_{2} \mathrm{O}_{3}$ in both compositions, BNA1 (Fig. 3b) and BA1 (Fig. 3c) compared to the neat LDPE (Fig. 3a). The micrographs reflect a more coarse dispersion of the filler into the matrix in case of not modified $\mathrm{Al}_{2} \mathrm{O}_{3}$ (Fig. 3b) and a good dispersion for the modified one (Fig. 3c). These results agree with those obtained in the optical and AFM microscopy studies. The alumina particles are well dispersed in the matrix due to good interaction between the filler particles and the polymer.

\subsection{Thermogravimetric Analysis (TGA)}

The thermal stability parameters, including initial decomposition temperature (IDT) and thermal degradation temperature (Td), were determined from the TG curves (Fig. 4a and Fig. 4b). From these figures, it is clear that the IDT value of the pristine LDPE is $390^{\circ} \mathrm{C}$, while the value for the composite with $1 \mathrm{wt} \%$ of treated $\mathrm{Al}_{2} \mathrm{O}_{3}$ is about $445^{\circ} \mathrm{C}$. Thus, this composite material presents an enhancement in its thermal stability of about $55^{\circ} \mathrm{C}$. In literature, there are several reports on the thermal stability of some polymer/filler composites was reported..$^{19,20}$

\subsection{Dielectric Properties}

The inorganic nanofillers have a strong influence on the permittivity of the resulting composites. Figure 5 shows the variation of the permittivity as a function of the $\mathrm{Al}_{2} \mathrm{O}_{3}$ loading for the studied composites. It can be seen that the composites values first increase with the increase of the filler load and then decrease, with an optimum value of $5.3 \cdot 10^{-7} \Omega^{-1} \mathrm{~cm}^{-1}$ at $1 \mathrm{wt} \%$ of the untreated filler and $6.6 .10^{-7} \Omega^{-1} \mathrm{~cm}^{-1}$ for the $1 \mathrm{wt} \%$ of treated one.

\section{Conclusions}

$\mathrm{LDPE} / \mathrm{Al}_{2} \mathrm{O}_{3}$ composites were successfully prepared using the co-mixing method and a Brabender plastograph. Part of the

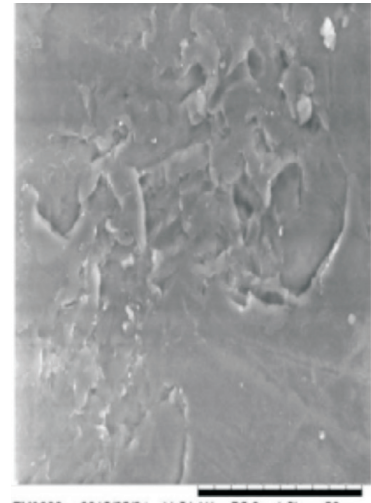

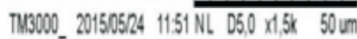
$S B R$

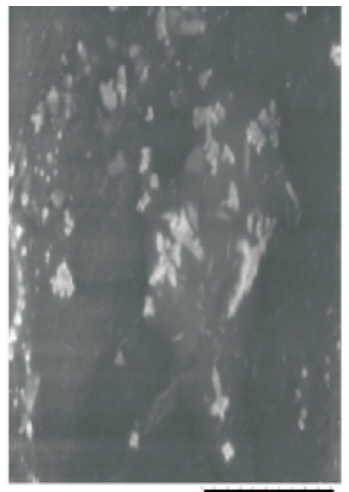

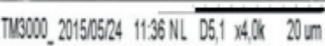
SBR

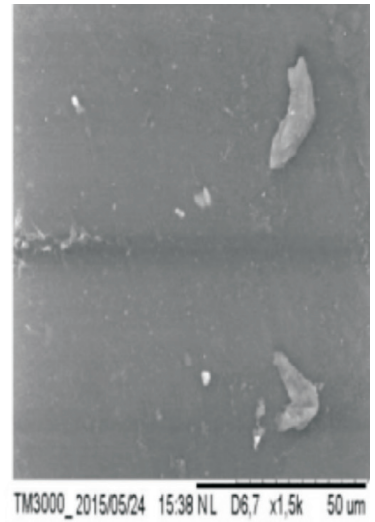

$S B R$

(b)

(c)

Figure 3 SEM micrographs of (a) pristine LDPE, (b) BNA1 and (c) BA1 composites. 

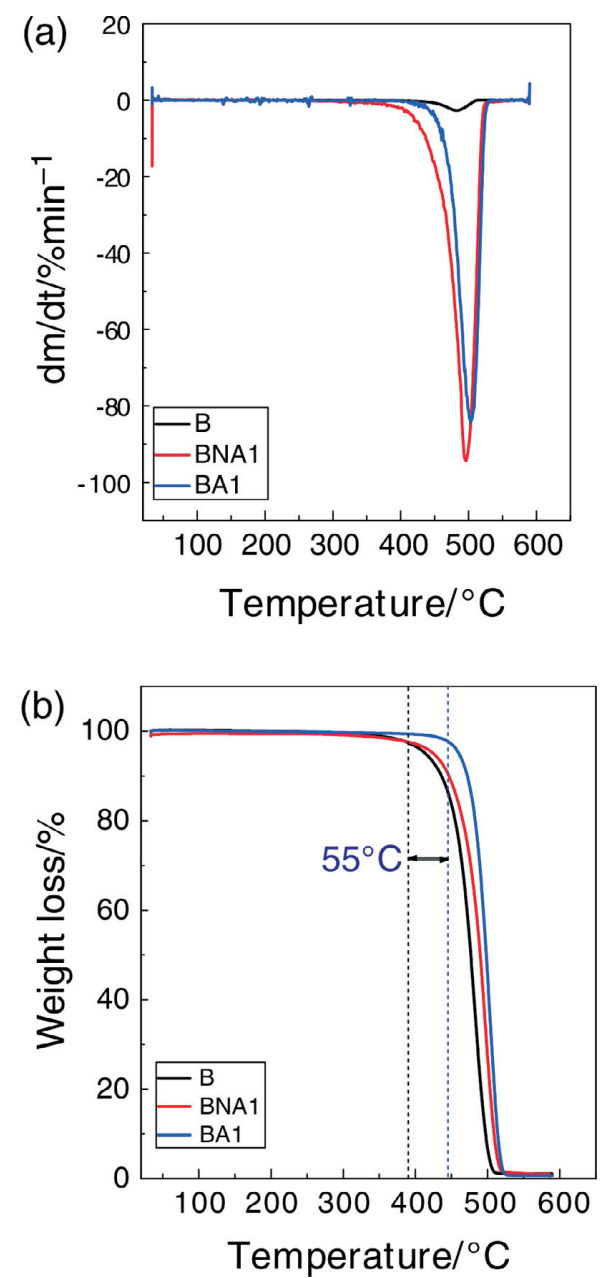

Figure 4 (a) TG curves of: (in black) pristine LDPE, (in red) BNA1 and (in blue) BA1 composites. (b) Weight loss curves of: (in black) pristine LDPE, (in red) BNA1 and (in blue) BA1 composites.

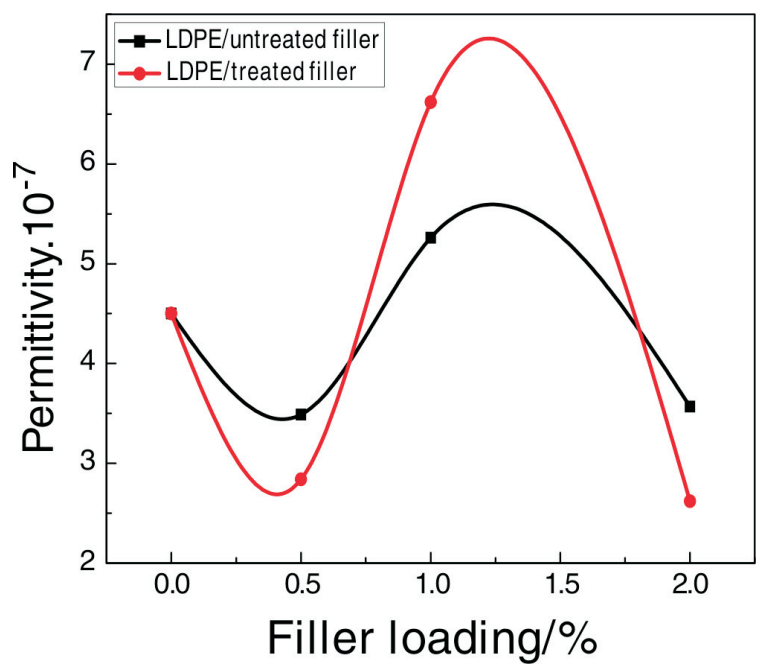

Figure 5 Variation of the dielectric permittivity of LDPE/untreated and treated $\mathrm{Al}_{2} \mathrm{O}_{3}$ composites as a function of the filler loading.

samples was prepared with $\mathrm{Al}_{2} \mathrm{O}_{3}$ modified by stearic acid, in order to achieve a better dispersion of the filler in the polymer matrix.

The morphological study results showed that, in case of the samples prepared with modified $\mathrm{Al}_{2} \mathrm{O}_{3}$, the stearic acid passed to the melt state and covered the $\mathrm{Al}_{2} \mathrm{O}_{3}$ particles ensuring a homogeneous dispersion of the treated filler into the matrix. This is an indication of the efficiency of the used method. This is confirmed by the AFM results, in which the roughness decreased from $334.05 \mathrm{~nm}$ to $63.25 \mathrm{~nm}$ for the treated $\mathrm{Al}_{2} \mathrm{O}_{3}$ in samples compared to the ones prepared with the not treated one.

Thermogravimetric analysis showed that $1 \mathrm{wt} \%$ of treated alumina has significantly improved the thermal stability of the composite by $55^{\circ} \mathrm{C}$.

The electric conductivity measurements show that the permittivity first increases and then decreases with an increase of the filler load, with an optimum value of $5.3 .10^{-7} \Omega^{-1} \mathrm{~cm}^{-1}$ for $1 \mathrm{wt} \%$ of the untreated filler and $6.6 .10^{-7} \Omega^{-1} \mathrm{~cm}^{-1}$ for $1 \mathrm{wt} \%$ of the treated one.

This result leads to the conclusion that the incorporation of $1 \mathrm{wt} \%$ of the treated $\mathrm{Al}_{2} \mathrm{O}_{3}$ improved significantly the thermal stability of the LDPE $/ \mathrm{Al}_{2} \mathrm{O}_{3}$ composites and their electric conductivity.

\section{${ }^{\S}$ ORCID iD}

M.E. Cagiao: (iD orcid.org/0000-0003-2763-1841

\section{REFERENCES}

1 A.A. Aly, E.B. Zeidan, A.A. Alshennawy, A.A. El-Masry and W.A. Wasel, Friction and wear of polymer composites filled by nanoparticles, World J. Nano Sci. Eng., 2012, 2, 32-39.

2 A.K. Bledzki and J. Gassan, Composites reinforced with cellulose based fibres, Prog. Polym. Sci., 1999, 24, 221-274.

3 P. Wambua, J. Ivens and I. Verpoest, Review of green polymer nanocomposites, Compos. Sci. Technol., 2003, 63, 1259-1264.

4 S.J. Eichhorn and R.J. Young, Materials design inspired by nature: function through inner architecture, Compos. Sci. Technol., 2004, 64, 767-772.

5 S.V. Joshi, L.T. Drzal, A.K. Mohanty and S. Arora, Are natural fiber composites environmentally superior to glass fiber reinforced composites?, Compos. Part A - Appl. Sci. Manuf., 2004, 35, 371-376.

6 M. Brahmakumar, C. Pavithran and R.M. Pillai, Investigating the effect of chemical treatment on the constituents and tensile properties of sisal fibre, Compos. Sci. Technol., 2005, 65, 563-569.

7 P J Herrera-Franco and A. Valadez-Gonzalez, A study of the mechanical properties of short natural-fiber reinforced composites, Compos. Part B - Eng., 2005, 36, 597-608.

8 M.W. Lertwimolnun, Réalisation de nanocomposites polypropylène/ argile par extrusion bivis, Thèse de Doctorat, École des Mines de Paris, 2006, 20-21.

9 S. Bouhelal, M.E. Cagiao, S. Khellaf, H. Tabet, B. Djellouli, D. Benachour and F.J. Baltá Calleja, Nanostructure and micromechanical properties of reversibly crosslinked isotactic polypropylene/clay composites, J. Appl. Polym. Sci., 2010, 115, 2654-2662.

10 F.Z. Benabid, L. Rong, D. Benachour, M.E. Cagiao, M. Ponçot, F. Zouai, S. Bouhelal and F.J. Baltá Calleja, Nanostructural characterization of poly (vinylidene fluoride)-clay nanocomposites prepared by onestep reactive extrusion process, J. Polym. Eng., 2015, 35,181.

11 F. Zouai, F.Z. Benabid, S. Bouhelal, M.E. Cagiao, D. Benachour and FJ. Baltá Calleja, Nanostructure and morphology of poly(vinylidene fluoride)/polymethyl (methacrylate)/clay nanocomposites: correlation to micromechanical properties, J. Mater. Sci., 2017, 52, 4345.

12 R. GuiHua, Y. ZhiSong and R. Xiong, Fabrication and optical properties of large-scale $\mathrm{ZnO}$ Nanotube bundles via a simple solution route, J. Wuhan Univ. Technol. - Mater. Sci. Ed., 2015, 30, 37.

13 K. Ishimoto, T. Tanaka, Y. Ohki, Y. Sekiguchi, Y. Murata and M. Goswami, Conference on Electrical Insulation and Dielectric Phenomena (CEIDP), Quebec, Canada, 2008, 26-29.

14 O.O. Daramola, I.O. Oladele, B.O. Adewuyi, J.L. Olajide, A.S. Ogunbadejo and P. Adeyemi, Tensile and hydrophilic properties of low-density polyethylene/titania composites, Leonardo J. Sci., 2016, $29,125-147$.

15 B. Nowak, J. Pajak and J. Karcz, Structure and properties of biodegradable polymer composites material, in Scan Electron Micros 32, Vlascheslaw Kazmiruk, 2012, 643-670.

16 W. Si-Jiao, Z. Jun-Wei, W. Yun-Hui, Y. Hong-DA and D. Zhi-Min, 
Polyethylene (LDPE) nanocomposites filled with nano alumina, $A m$. J. Eng. Appl. Sci., 2015, 8, 405-409.

17 F. Ciuprina, T. Zaharescu and I. Pleşa, Effects of $\gamma$-radiation on dielectric properties of LDPE- $\mathrm{Al}_{2} \mathrm{O}_{3}$ nanocomposites, Rad. Phys. Chem., 2013, 84, 145-150.

18 O.K. Mallem, Etude des propriétés physico-chimiques des composites $\mathrm{PP} / \mathrm{Al}_{2} \mathrm{O}_{3}$ et $\mathrm{PEBD} / \mathrm{Al}_{2} \mathrm{O}_{3}$, Mémoire de Master, Université Ferhat ABBAS, Sétif-1, Algeria, 2015.
19 P. Rajeshwari and T.K. Dey, Influence of surface modified nanoilmenite/amorphous silica composite particles on the thermal stability of cold galvanizing coating, J. Therm. Anal. Calorim., 2014, 118, 1513-1530.

20 H.K.F. Cheng, M.F. Chong, E. Liu, K. Zhou and L. Li, Thermal decomposition kinetics of multiwalled carbon nanotube/polypropylene nanocomposites, J. Therm. Anal. Calorim., 2014, 117, 63-71. 